\title{
Predicting the Glomerular Filtration Rate in Bariatric Surgery Patients
}

\author{
Allon N. Friedman ${ }^{a}$ Sharon Moe ${ }^{a, d}$ William F. Fadel ${ }^{e}$ Margaret Inman ${ }^{f}$ \\ Samer G. Mattar ${ }^{b}$ Zak Shihabig Sara K. Quinney ${ }^{a, c}$ \\ Departments of a Medicine, b Surgery and c Obstetrics and Gynecology, Indiana University School of Medicine, \\ ${ }^{\mathrm{d}}$ Department of Medicine, Roudebush Veterans Affairs Medical Center, e Department of Biostatistics, \\ Indiana University School of Public Health, Indianapolis, Ind., ${ }^{\text {} M e r i d i a n ~ S u r g i c a l ~ G r o u p ~ I n c ., ~ C a r m e l, ~ I n d ., ~ a n d ~}$ \\ ${ }^{9}$ Department of Pathology, Wake Forest University School of Medicine, Winston-Salem, N.C., USA
}

\section{Key Words}

Obesity · Bariatric surgery · Glomerular filtration rate .

Creatinine $\cdot$ Cystatin $C \cdot$ Weight loss $\cdot$ Estimating equation

\begin{abstract}
Background/Aims: Identifying the best method to estimate the glomerular filtration rate (GFR) in bariatric surgery patients has important implications for the clinical care of obese patients and research into the impact of obesity and weight reduction on kidney health. We therefore performed such an analysis in patients before and after surgical weight loss. Methods: Fasting measured GFR (mGFR) by plasma iohexol clearance before and after bariatric surgery was obtained in 36 severely obese individuals. Estimated GFR was calculated using the Modification of Diet in Renal Disease equation, the Chronic Kidney Disease Epidemiology Collaboration (CKD-EPI) equation using serum creatinine only, the CKD-EPI equation using serum cystatin C only and a recently derived equation that uses both serum creatinine and cys-

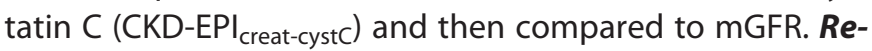
sults: Participants were primarily middle-aged white females with a mean baseline body mass index of $46 \pm 9$, serum creatinine of $0.81 \pm 0.24 \mathrm{mg} / \mathrm{dl}$ and $\mathrm{mGFR}$ of $117 \pm 40$ $\mathrm{ml} / \mathrm{min}$. $\mathrm{mGFR}$ had a stronger linear relationship with inverse cystatin $C$ before $(r=0.28, p=0.09)$ and after $(r=0.38, p=$
\end{abstract}

0.02) surgery compared to the inverse of creatinine (before: $r=0.26, p=0.13$; after: $r=0.11, p=0.51)$. mGFR fell by $17 \pm$ $35 \mathrm{ml} / \mathrm{min}(p=0.007)$ following surgery. The CKD-EPI creat-cystC was unquestionably the best overall performing estimating equation before and after surgery, revealing very little bias and a capacity to estimate mGFR within $30 \%$ of its true value over $80 \%$ of the time. This was true whether or not mGFR was indexed for body surface area. Conclusions: In severely obese bariatric surgery patients with normal kidney function, cystatin $C$ is more strongly associated with mGFR than is serum creatinine. The CKD-EPI creat-cystc $_{\text {equation best pre- }}$ dicted mGFR both before and after surgery.

(c) 2013 S. Karger AG, Basel

\section{Introduction}

Bariatric surgery is a common and effective treatment for severe obesity, a problem of global proportions that is linked to a variety of adverse clinical outcomes [1]. Bariatric surgery is of interest to nephrologists not only because it is associated with an increased risk for both acute and chronic kidney injury [2] but also because it serves as a research model to investigate the relationship between obesity, weight reduction and kidney health. Investigations using the bariatric surgery model suggest that weight

\section{KARGER}

E-Mail karger@karger.com

www.karger.com/ajn
(C) 2013 S. Karger AG, Basel

0250-8095/13/0391-0008\$38.00/0
Allon Friedman, MD

550 University Blvd.

Suite 6100

Indianapolis, IN 46202 (USA)

E-Mail allfried@iu.edu 
loss in obese persons may have renoprotective effects [3, $4]$, although the body of evidence relies primarily on estimated glomerular filtration rate (eGFR) rather than directly measured GFR (mGFR). Similarly, clinical evaluations of bariatric surgery patients also depend on eGFR.

Unfortunately, the value of eGFR in bariatric surgery patients using standard estimating equations, the most common clinical method, may be limited. There are several reasons for this. Firstly, the equations were derived from mostly nonobese populations [5-7]. Because serum creatinine is derived from muscle mass, and the muscle mass of severely obese individuals is greater than that of leaner individuals of similar height, this could adversely affect the reliability of the equations [8]. Additionally, weight loss after surgery involves reductions in muscle as well as fat mass [9]. Further complicating this issue is the fact that elevations in glomerular filtration (often called hyperfiltration), which cause a drop in serum creatinine levels, are frequently observed in obese individuals and reversed when weight is lost [10]. Cystatin C, an alternative endogenous marker of glomerular filtration, is arguably not as influenced by muscle mass as is serum creatinine [11], so it may be a more reliable indicator of kidney function in obese individuals. However, it is notable that none of the best validated creatinine- or cystatin-based estimating equations has been carefully evaluated in very obese or bariatric surgery patients.

We therefore assessed the reliability of the most prominent GFR equations and endogenous GFR markers in a cohort of severely obese patients with putatively normal kidney function before and after bariatric surgery by comparing eGFR to mGFR. We hypothesized that cystatin C-based eGFR would better predict mGFR than estimations based on serum cystatin C.

\section{Subjects and Methods}

\section{Participants}

Study participants were part of several research projects performed between 2004 and 2011 [12, 13, 44] and were recruited from bariatric surgery clinics in the Indianapolis (Ind., USA) area. All subjects except 1 [body mass index (BMI) of 33] were severely obese, defined as a $\mathrm{BMI} \geq 35$. The relevant institutional review boards approved the protocol (NCT00244790), and all patients gave written informed consent after reviewing a written summary of the plan. The study adhered to the Declaration of Helsinki. A data safety and monitoring board oversaw the study. Inclusion criteria included age 18 or greater, ability to give informed consent and a BMI of 30 or higher. Exclusion criteria included pregnancy, an iodine allergy, a diagnosis of diabetes mellitus, use of an angiotensin-converting enzyme inhibitor or angiotensin receptor block- er, serum creatinine $>1.3 \mathrm{mg} / \mathrm{dl}$ for women and $>1.5 \mathrm{mg} / \mathrm{dl}$ for men, or dialysis dependency. Pregnancy was excluded by a urine pregnancy test on the day of study. Presurgery measurements were performed within the 6-month period prior to surgery, and postsurgery measurements were performed at varying time points depending upon the study protocol (several months to over 1 year), with the mean postoperative measurement time point being approximately 10 months.

\section{Measurements}

mGFR was calculated from plasma iohexol (Omnipaque-300, GE Healthcare, Piscataway, N.J., USA) clearance. Plasma was isolated and stored at $-80^{\circ} \mathrm{C}$ until measured by capillary electrophoresis using a Model $2050 \mathrm{CE}$ instrument (Beckman Instruments, Palo Alto, Calif., USA) as previously reported [12, 13] or HPLC (Agilent 1100, Santa Clara, Calif., USA) with UV detection. Individual iohexol clearances (milliliters per minute) were estimated by standard noncompartmental methods using Phoenix WinNonlin (Pharsight, Cary, N.C., USA). Iohexol clearance was calculated as dose divided by the area under the plasma concentration-time curve from time zero to infinity. In cases where only 2 plasma concentrations were available per individual, population pharmacokinetic methods were used as previously described [13]. BMI and body surface area (BSA) [14] were calculated during each visit from measured weight and height with the subject wearing a hospital gown and no shoes. Serum creatinine was measured using the Roche/Hitachi Creatinine Plus enzymatic assay (Roche Diagnostics, Basel, Switzerland) traceable to an isotope dilution mass spectrometry method and serum cystatin $\mathrm{C}$ by the immunoturbidimetric method (Roche Cobas 6000, Basel, Switzerland).

\section{Statistical Methods}

All linear associations were assessed using Pearson's correlation coefficient and tested using Fisher's z transformation. Differences between pre- and postsurgery measurements were assessed using paired $t$ tests, and results are presented as means \pm standard error. The statistical analyses used SAS, version 9.3 (SAS Institute, Cary, N.C., USA) and R, version 2.15 (Free Software Foundation, Boston, Mass., USA).

\section{Metrics for Equation Performance}

eGFR was calculated using 1 of the following 4 well-validated equations: the Modification of Diet in Renal Disease equation using standardized serum creatinine values [15]; the Chronic Kidney Disease Epidemiology Collaboration (CKD-EPI) equation using serum creatinine only [5]; the CKD-EPI equation using serum cystatin C only $[16,17]$, and a recently derived equation that uses both serum creatinine and cystatin C $\left(\mathrm{CKD}-\mathrm{EPI}_{\text {creat-cystC }}\right)$ [7]. eGFR (milliliters per minute per $1.73 \mathrm{~m}^{2}$ ) was compared to mGFR (milliliters per minute) after converting them both to milliliters per minute or milliliters per minute per $1.73 \mathrm{~m}^{2}$. The conversion was performed using the following equation: GFR $(\mathrm{ml} / \mathrm{min})=\mathrm{GFR}$ $\left(\mathrm{ml} / \mathrm{min} / 1.73 \mathrm{~m}^{2}\right) \times \mathrm{BSA} / 1.73$ [18]. Bias was defined as the median difference between eGFR and mGFR and expresses the systematic deviation from mGFR. We defined precision as the interquartile range for the differences since it expresses the variability or dispersion around mGFR. Accuracy, which combines bias and precision, was defined as the root mean square error relative to mGFR and the percentage of estimates within $15 \%$ and $30 \%\left(\mathrm{P}_{30}\right)$ of the mGFR. 
Table 1. Subject characteristics

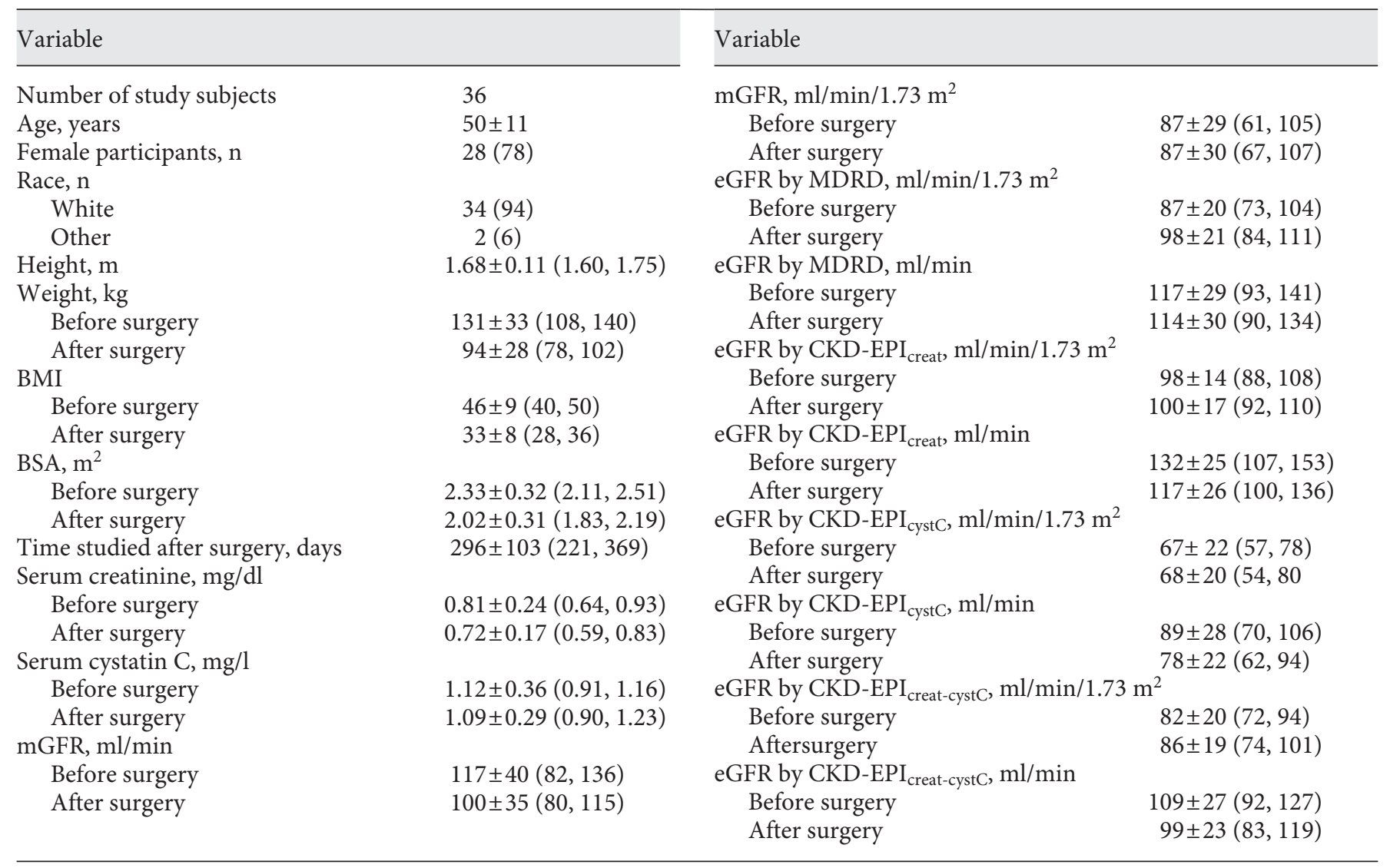

Values represent numbers of patients (percentage) or means $\pm \mathrm{SD}$ (25th, 75th percentiles), as appropriate. eGFR was converted by means of the following equation: eGFR $(\mathrm{ml} / \mathrm{min})=\mathrm{eGFR}\left(\mathrm{ml} / \mathrm{min} / 1.73 \mathrm{~m}^{2}\right) \times \mathrm{BSA}\left(\mathrm{m}^{2}\right) / 1.73$. CKD-EPI creat $=$ CKD-EPI equation using serum creatinine only; $\mathrm{CKD}-\mathrm{EPI}_{\mathrm{cystC}}=\mathrm{CKD}$-EPI equation using serum cystatin $\mathrm{C}$ only. $\mathrm{CKD}-\mathrm{EPI} \mathrm{I}_{\text {creat-cystC }}=\mathrm{CKD}$-EPI equation using serum creatinine and cystatin $\mathrm{C}$.

\section{Results}

Participant characteristics before and after surgery are shown in table 1 . The 36 study participants were primarily middle-aged, white females who were severely obese by BMI criteria. Nearly all participants had baseline serum creatinine and cystatin $C$ levels that were within the normal range, and many manifested supranormal (hyperfiltering) levels of mGFR before surgery. Participants were studied an average of 10 months after bariatric surgery, at which time a mean of $37 \mathrm{~kg}$ had been lost $(\mathrm{p}<$ 0.001 ), with mean $\mathrm{mGFR}$ being $17 \pm 6 \mathrm{ml} / \mathrm{min}$ lower than presurgery levels ( $p=0.007$; fig. 1$)$. mGFR was not significantly associated with weight (before: $p=0.12$; after: $\mathrm{p}=0.20$ ) or BSA (before: $\mathrm{p}=0.18$; after: $\mathrm{p}=0.22$ ) before or after surgery. Change in mGFR was nonsignificantly correlated with change in weight $(\mathrm{p}=0.08)$ but not time after surgery $(\mathrm{p}=0.49)$.

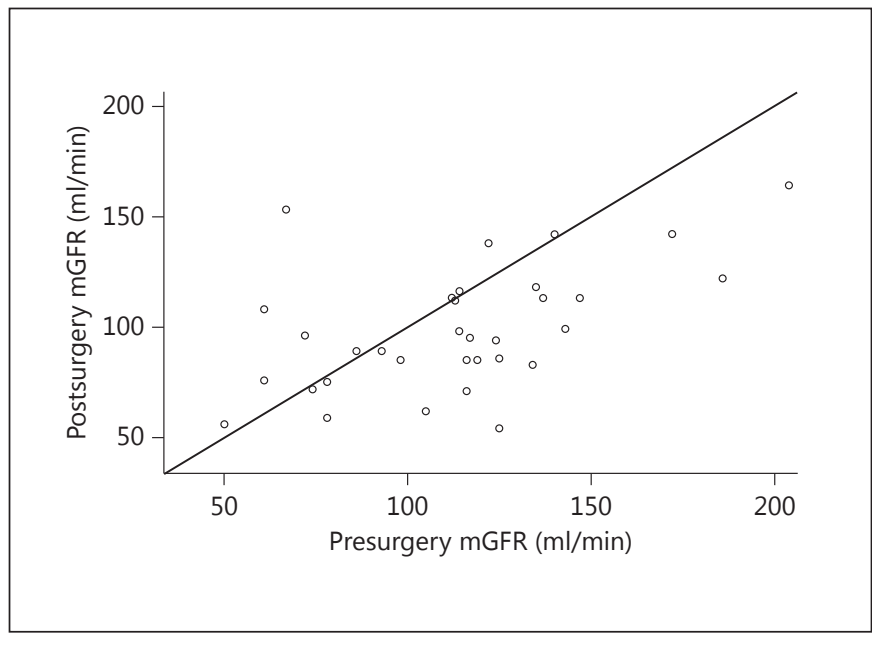

Fig. 1. mGFR before and after surgery.
10

Am J Nephrol 2014;39:8-15

DOI: $10.1159 / 000357231$
Friedman/Moe/Fadel/Inman/Mattar/ Shihabi/Quinney 

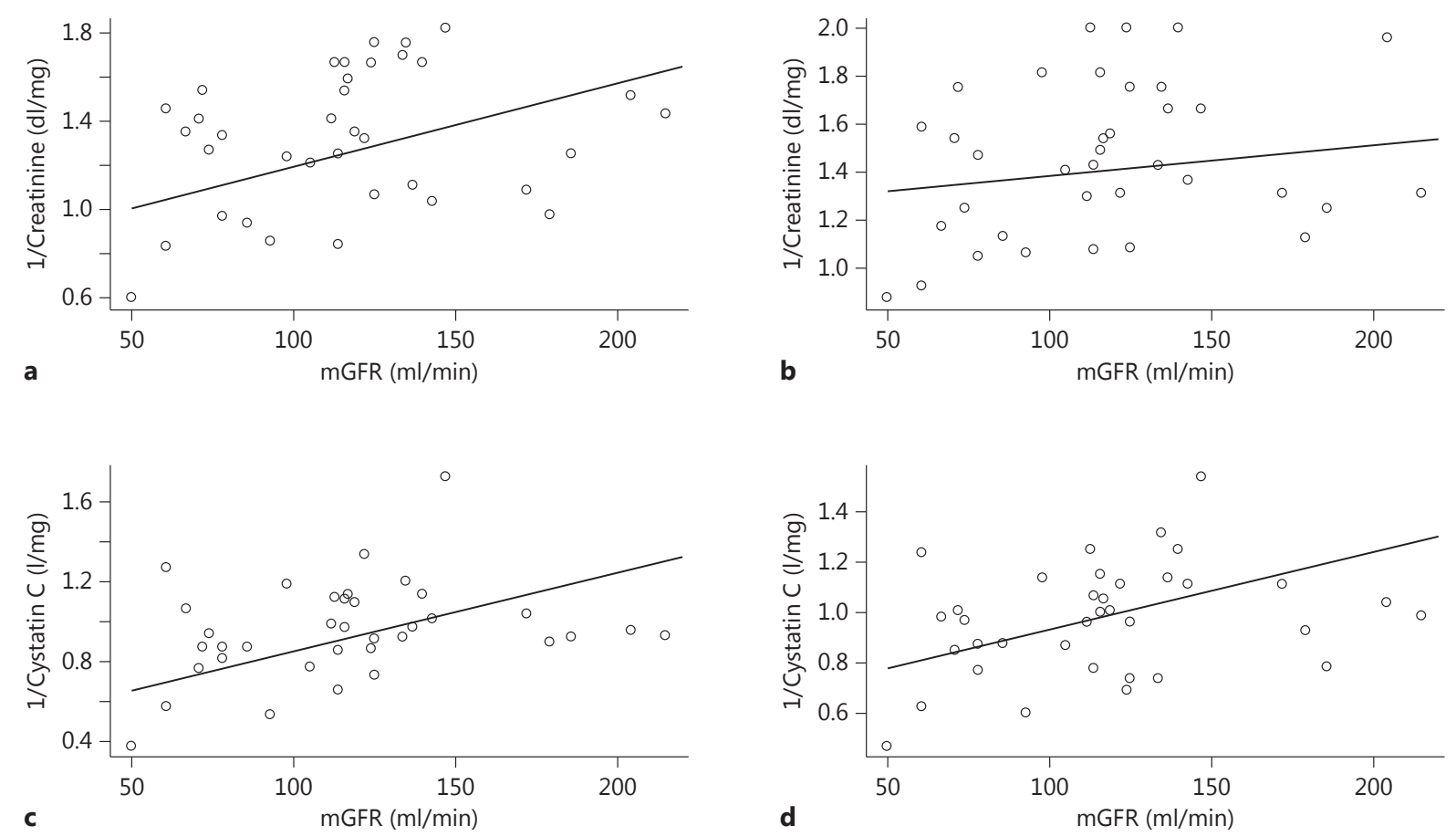

Fig. 2. $\mathbf{a}, \mathbf{b}$ mGFR versus inverse creatinine before surgery $(\mathbf{a} ; \mathrm{r}=0.26, \mathrm{p}=0.13)$ and after surgery $(\mathbf{b} ; \mathrm{r}=0.11$, $\mathrm{p}=0.51) . \mathbf{c}, \mathbf{d}$ mGFR versus inverse cystatin C before surgery $(\mathbf{c} ; \mathrm{r}=0.28, \mathrm{p}=0.09)$ and after surgery $(\mathbf{d} ; \mathrm{r}=0.38$, $\mathrm{p}=0.02)$.

Serum creatinine dropped significantly after surgery $(0.1 \pm 0.02 \mathrm{mg} / \mathrm{dl} ; \mathrm{p}<0.001)$, but mean cystatin $\mathrm{C}$ did not change $(0.03 \pm 0.03 \mathrm{mg} / \mathrm{l} ; \mathrm{p}=0.20)$. Weight before and after surgery was more closely associated with cystatin $\mathrm{C}$ (before: $\mathrm{r}=0.43, \mathrm{p}=0.009$; after: $\mathrm{r}=0.49, \mathrm{p}=0.003$ ) than serum creatinine (before: $\mathrm{r}=0.40, \mathrm{p}=0.02$; after: $\mathrm{r}=0.41$, $\mathrm{p}=0.01)$, though change in weight was not correlated with either variable. After surgery, mGFR was significantly associated with the inverse of cystatin $\mathrm{C}(\mathrm{r}=0.38, \mathrm{p}=$ $0.02)$. However, this relationship did not reach statistical significance in individuals before surgery $(\mathrm{r}=0.28, \mathrm{p}=$ 0.09 ). The inverse of creatinine was not significantly correlated with $\mathrm{mGFR}$ either before or after surgery (before: $\mathrm{r}=0.26, \mathrm{p}=0.13$; after: $\mathrm{r}=0.11, \mathrm{p}=0.51$; fig. 2).

The overall reliability of GFR-estimating equations is shown in table 2 . After expressing both eGFR and $\mathrm{mGFR}$ in milliliters per minute, the CKD-EPI ${ }_{\text {creat-cystC }}$ was unquestionably the best overall performing estimating equation, showing very little bias and $\mathrm{P}_{30}$ of over $80 \%$. Preci- sion and accuracy for the CKD-EPI creat-cystC $_{\text {equation fur- }}$ ther improved after surgery, with $\mathrm{P}_{30}$ increasing to over $83 \%$. After indexing eGFR and mGFR for BSA (i.e. making the units milliliters per minute per $1.73 \mathrm{~m}^{2}$ ), bias and accuracy both improved modestly, while precision after surgery fell slightly.

\section{Discussion}

Identifying a method that best estimates GFR in bariatric surgery patients before and after weight loss has important implications for clinical care of obese patients and research questions related to the impact of obesity and weight reduction on kidney health. In the first study of its kind, we evaluated which of the most validated creatinine- and cystatin C-based GFR-estimating equations best predicts $\mathrm{mGFR}$ in a cohort of bariatric surgery patients. We found that the CKD-EPI creat-cystC $_{\text {equation per- }}$ 
Table 2. Comparison of eGFR and mGFR before and after bariatric surgery

\begin{tabular}{|c|c|c|c|c|}
\hline & \multicolumn{2}{|c|}{ Before surgery } & \multicolumn{2}{|c|}{ After surgery } \\
\hline & mGFR & eGFR & mGFR & eGFR \\
\hline \multicolumn{5}{|l|}{ Bias, median difference ${ }^{\mathrm{a}}$} \\
\hline MDRD & -9.0 & -7.0 & -18.5 & -15.2 \\
\hline CKD-EPI creat & -18.2 & -13.5 & -20.0 & -18.7 \\
\hline CKD-EPI $I_{\text {cystC }}$ & 22.6 & 15.6 & 18.2 & 15.6 \\
\hline CKD-EPI ${ }_{\text {creat-cystC }}$ & 1.6 & 1.0 & -4.7 & -3.9 \\
\hline \multicolumn{5}{|c|}{ Precision, IQR of difference ${ }^{\mathrm{a}}$} \\
\hline MDRD & 41.3 & 33.8 & 27.0 & 30.4 \\
\hline CKD-EPI ${ }_{\text {creat }}$ & 46.9 & 33.0 & 33.0 & 29.6 \\
\hline CKD-EPI cystC $_{\text {cht }}$ & 45.1 & 36.3 & 28.4 & 29.9 \\
\hline CKD-EPI ${ }_{\text {creat-cystC }}$ & 35.0 & 28.4 & 21.6 & 23.4 \\
\hline \multicolumn{5}{|c|}{ Accuracy, root mean square error } \\
\hline MDRD & 0.34 & 0.26 & 0.36 & 0.30 \\
\hline CKD-EPI ${ }_{\text {creat }}$ & 0.37 & 0.27 & 0.36 & 0.30 \\
\hline CKD-EPI ${ }_{\text {cystC }}$ & 0.46 & 0.34 & 0.35 & 0.30 \\
\hline CKD-EPI creat-cystC & 0.34 & 0.26 & 0.27 & 0.23 \\
\hline \multicolumn{5}{|l|}{ Accuracy, \% } \\
\hline \multicolumn{5}{|l|}{$\mathrm{P}_{15}$} \\
\hline MDRD & 30.6 & 30.6 & 30.6 & 30.6 \\
\hline CKD-EPI ${ }_{\text {creat }}$ & 44.4 & 44.4 & 30.6 & 30.6 \\
\hline CKD-EPI ${ }_{\text {cystC }}$ & 30.6 & 30.6 & 27.8 & 27.8 \\
\hline CKD-EPI ${ }_{\text {creat-cystC }}$ & 41.7 & 41.7 & 58.3 & 58.3 \\
\hline \multicolumn{5}{|l|}{$\mathrm{P}_{30}$} \\
\hline MDRD & 72.2 & 72.2 & 55.6 & 55.6 \\
\hline CKD-EPI ${ }_{\text {creat }}$ & 58.3 & 58.3 & 52.8 & 52.8 \\
\hline CKD-EPI ${ }_{\text {cystC }}$ & 52.8 & 52.8 & 66.7 & 66.7 \\
\hline CKD-EPI creat-cystC & 80.6 & 80.6 & 83.3 & 83.3 \\
\hline
\end{tabular}

$\mathrm{CKD}-\mathrm{EPI}_{\text {creat }}=\mathrm{CKD}-\mathrm{EPI}$ equation using serum creatinine only; $\mathrm{CKD}-\mathrm{EPI}_{\text {cystC }}=\mathrm{CKD}-\mathrm{EPI}$ equation using serum cystatin $\mathrm{C}$ only; $\mathrm{CKD}-\mathrm{EPI}_{\text {creat-cystC }}=\mathrm{CKD}$-EPI equation using both serum creatinine and cystatin C; $\mathrm{IQR}=$ interquartile range; $\mathrm{P}_{15}=$ percentage of estimates that differed from mGFR by more than $15 \%$.

${ }^{a}$ In milliliters per minute for each left-hand column and milliliters per minute per $1.73 \mathrm{~m}^{2}$ for each right-hand column.

formed the best before and after surgery, regardless of whether or not indexing for BSA was used.

The influence of severe obesity on the assessment of GFR has been insufficiently studied, particularly in light of its relatively high prevalence (nearly $16 \%$ of the US adult population has a BMI $\geq 35$ ) [19] and association with acute and chronic kidney disease [20-23]. While mGFR is the gold standard for assessing kidney function, it involves techniques that are expensive, cumbersome and invasive. In addition, mGFR has its limitations, such as wide variability within individuals and between methods and a lack of benefit over eGFR in predicting outcomes [24]. eGFR has therefore evolved as the standard in the clinical setting. Moreover, even the great majority of research studies examining GFR before and after bariatric surgery use creatinine-based GFR-estimating equations rather than direct measurements $[4,25,26]$. Nevertheless, the use of eGFR in bariatric surgery patients is fraught with potential limitations. Obese persons have proportionally greater muscle mass compared to lean individuals of similar height [8]. This leads to greater creatinine release into the bloodstream and subsequently higher serum creatinine levels when the GFR is constant. In addition, obesity is frequently associated with glomerular hyperfiltration [27] (as noted in our study population), which results in lower steady-state serum creati-
12

Am J Nephrol 2014;39:8-15

DOI: $10.1159 / 000357231$
Friedman/Moe/Fadel/Inman/Mattar/ Shihabi/Quinney 
nine levels. The result of these multiple and sometimes opposing influences is that the predictive ability of creatinine-based GFR-estimating equations, none of which were derived or validated in very obese populations $[5,7$, 15], is unknown, which is why it is so important to validate eGFR in this particular patient subgroup.

Cystatin $\mathrm{C}$ is an endogenous glomerular filtration marker that is being studied as an alternative or complement to creatinine. There is reason to believe that serum cystatin C may correlate more closely with GFR than serum creatinine, particularly in subjects with lower creatinine levels [28, 29]. In addition, it is a better predictor of adverse outcomes [30,31]. Several studies suggest that unlike creatinine, cystatin $\mathrm{C}$ is minimally affected by dietary meat consumption [32] or muscle mass [11,33], although controversy still exists over the latter issue [34, 35]. One particularly compelling report demonstrated that cystatin $\mathrm{C}$ levels do not drop after traumatic limb amputations, further suggesting that, unlike with serum creatinine, cystatin $\mathrm{C}$ is not influenced by lean mass [36]. The fact that serum cystatin $\mathrm{C}$ may be less influenced by body composition than creatinine is not only relevant to estimating GFR in severely obese individuals (who have relatively increased lean mass) but also important to understanding how best to estimate GFR in very obese persons who undergo intentional weight loss because this typically results in loss of both fat and muscle [37]. In our study, serum cystatin $\mathrm{C}$ was observed to have a stronger correlation with mGFR than did serum creatinine. In addition, cystatin $\mathrm{C}$ also had a statistically significant association with body weight (though weight did not have a similar association with mGFR). These findings suggest that while cystatin $\mathrm{C}$ appears to be more closely linked to mGFR and is itself a superior marker of GFR in this population, it is also likely to be influenced by additional factors. Perhaps adipose mass or its secreted inflammatory products account for the observed relationship between weight and cystatin C $[38,39]$.

An additional issue pertinent to estimating GFR in bariatric surgery patients is the standard of indexing of GFR for BSA in GFR-estimating equations. Adjusting for BSA allows for comparison of GFR between individuals of differing body size, with the underlying assumption being that physiological parameters like GFR are proportional to body size. This is supported by allometric scaling principles in which larger-sized organisms produce a greater metabolic load that leads to a greater filtration capacity [40]. However, as we and others have pointed out $[41,42]$, applying these concepts to the obese individual is misleading. Obese persons are different than lean sub- jects in that increases in weight are mostly due to excess adiposity, not lean mass. This difference is important because adipose mass does not significantly contribute to metabolic load [43]. Therefore, adjusting for BSA in obese individuals underestimates the true GFR. Consistent with our concern is the fact that we observed no significant relationship between mGFR and parameters like weight or BSA in this severely obese population. Furthermore, if one is interested specifically in determining the change in GFR after weight reduction within a particular individual, then adjusting for BSA is unnecessary because the number of nephrons does not change as the individual loses weight. While the CKD-EPI creat-cystC $_{\text {equation performed }}$ similarly with and without indexing for BSA, we believe that indexing should preferably be avoided when studying changes within an individual bariatric surgery patient.

Several prominent, well-validated GFR-estimating equations were evaluated in our study population. Though

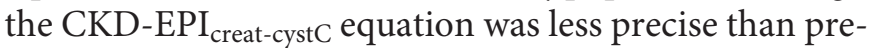
viously reported in leaner populations $[5,7]$, its bias and accuracy were similar to those of equations used in standard clinical practice (e.g. Modification of Diet in Renal Disease equation, CKD-EPI equation using serum creatinine only) [5]. Interestingly, the combination of serum cystatin $\mathrm{C}$ and creatinine greatly improved the predictive value of eGFR over individual creatinine- or cystatin Cbased equations. This is surprising, as we expected the cystatin C-based equation to perform better than creatinine-based equations, which it did not. We hypothesize that various influences on creatinine and cystatin $\mathrm{C}$ that are unrelated to GFR balanced each other and resulted in improved overall performance.

Our study has several strengths. It is the first study to assess the predictive value of estimating equations before and after bariatric surgery-induced weight loss using a cohort of bariatric surgery patients in whom GFR was directly measured. It therefore provides novel and important information that can be applied to clinical practice and the research setting. It also has some limitations. Our study is of a relatively modest size (though we are unaware of larger studies directly measuring GFR in bariatric surgery patients). The study was performed in patients with normal baseline serum creatinine levels, so caution should be used when applying the findings to patients with existing kidney disease. Body composition measurements were not available for the cohort, which could have helped further define the influence of lean versus fat mass on mGFR. We did not specifically exclude patients who may have had diseases (hypothyroidism) or taken medi- 
cations (glucocorticoids) that could influence cystatin C levels. However, such issues were unlikely to affect our findings in light of the relatively healthy nature of our study population. We also did not measure dietary protein consumption, which could influence serum creatinine levels though is unlikely to influence mGFR [44].

In conclusion, cystatin $\mathrm{C}$ is more strongly associated with mGFR than is serum creatinine in bariatric surgery patients, while the CKD-EPI $I_{\text {creat-cystC }}$ equation best predicted mGFR both before and after surgery.

\section{Acknowledgements}

This study was supported by the NIH (5K23RR019615), Dialysis Clinics Inc. and the Indiana Clinical and Translational Sciences Institute (grant number TR000006).

\section{Disclosure Statement}

None of the authors have any conflict of interest to report.

\section{References}

1 Ezzati M, Riboli E: Behavioral and dietary risk factors for noncommunicable diseases. N Engl J Med 2013;369:954-964.

2 Friedman A: Implications and management of obesity in kidney disease; in Byham-Gray L, Burrows J, Chertow G (eds): Nutrition in Kidney Disease. New York, Springer, in press.

-3 Navaneethan SD, Yehnert H, Moustarah F, Schreiber MJ, Schauer PR, Beddhu S: Weight loss interventions in chronic kidney disease: a systematic review and meta-analysis. Clin J Am Soc Nephrol 2009;4:1565-1574.

4 Neff KJ, Frankel AH, Tam FW, Sadlier DM, Godson C, le Roux CW: The effect of bariatric surgery on renal function and disease: a focus on outcomes and inflammation. Nephrol Dial Transplant 2013;28(suppl 4):iv73-iv82.

$\checkmark 5$ Levey AS, Stevens LA, Schmid CH, Zhang YL, Castro AF 3rd, Feldman HI, Kusek JW, Eggers P, Van Lente F, Greene T, Coresh J: A new equation to estimate glomerular filtration rate. Ann Intern Med 2009;150:604-612.

6 Levey AS, Bosch JP, Lewis JB, Greene T, Rogers N, Roth D: A more accurate method to estimate glomerular filtration rate from serum creatinine: a new prediction equation. Modification of Diet in Renal Disease Study Group. Ann Intern Med 1999;130:461-470.

-7 Inker LA, Schmid CH, Tighiouart H, Eckfeldt JH, Feldman HI, Greene T, Kusek JW, Manzi J, Van Lente F, Zhang YL, Coresh J, Levey AS; CKD-EPI Investigators: Estimating glomerular filtration rate from serum creatinine and cystatin C. N Engl J Med 2012;367:20-29.

$\checkmark 8$ James WP, Dauncey MJ, Davies HL: Elevated metabolic rates in obesity. Lancet 1978;ii:472.

-9 Tamboli RA, Hossain HA, Marks PA, Eckhauser AW, Rathmacher JA, Phillips SE, Buchowski MS, Chen KY, Abumrad NN: Body composition and energy metabolism following roux-en-y gastric bypass surgery. Obesity (Silver Spring) 2010;18:1718-1724.

10 Chagnac A, Weinstein T, Herman M, Hirsh J, Gafter U, Ori Y: The effects of weight loss on renal function in patients with severe obesity. J Am Soc Nephrol 2003;14:1480-1486.
Baxmann AC, Ahmed MS, Marques NC, Menon VB, Pereira AB, Kirsztajn GM, Heilberg IP: Influence of muscle mass and physical activity on serum and urinary creatinine and serum cystatin c. Clin J Am Soc Nephrol 2008; 3:348-354

12 Friedman AN, Yu Z, Juliar BE, Nguyen JT, Strother M, Quinney SK, Li L, Inman M, Gomez G, Shihabi Z, Moe S: Independent influence of dietary protein on markers of kidney function and disease in obesity. Kidney Int 2010;78:693-697.

13 Friedman AN, Strother M, Quinney SK, Hall S, Perkins SM, Brizendine EJ, Inman M, Gomez G, Shihabi Z, Moe S, Li L: Measuring the glomerular filtration rate in obese individuals without overt kidney disease. Nephron Clin Pract 2010;116:c224-c234.

14 DuBois D, DuBois E: A formula to estimate the approximate surface area if height and weight be known. Arch Intern Med 1916;17: 863-871.

15 Levey AS, Coresh J, Greene T, Stevens LA, Zhang YL, Hendriksen S, Kusek JW, Van Lente F: Using standardized serum creatinine values in the modification of diet in renal disease study equation for estimating glomerular filtration rate. Ann Intern Med 2006;145: 247-254.

16 Inker LA, Eckfeldt J, Levey AS, LeiendeckerFoster C, Rynders G, Manzi J, Waheed S, Coresh J: Expressing the CKD-EPI (Chronic Kidney Disease Epidemiology Collaboration) cystatin C equations for estimating GFR with standardized serum cystatin $\mathrm{C}$ values. Am J Kidney Dis 2011;58:682-684.

17 Stevens LA, Coresh J, Schmid CH, Feldman HI, Froissart M, Kusek J, Rossert J, Van Lente F, Bruce RD 3rd, Zhang YL, Greene T, Levey AS: Estimating GFR using serum cystatin C alone and in combination with serum creatinine: a pooled analysis of 3,418 individuals with CKD. Am J Kidney Dis 2008;51:395406.

18 National Kidney Foundation: Frequently Asked Questions about GFR Estimates. New York, National Kidney Foundation, 2011.
19 Flegal KM, Carroll MD, Kit BK, Ogden CL: Prevalence of obesity and trends in the distribution of body mass index among US adults, 1999-2010. JAMA 2012;307:491-497.

20 de Boer IH, Rue TC, Hall YN, Heagerty PJ, Weiss NS, Himmelfarb J: Temporal trends in the prevalence of diabetic kidney disease in the United States. JAMA 2011;305:25322539.

21 Weingarten TN, Gurrieri C, McCaffrey JM, Ricter SJ, Hilgeman ML, Schroeder DR, Kendrick ML, Greene EL, Sprung J: Acute kidney injury following bariatric surgery. Obes Surg 2013;23:64-70.

$22 \mathrm{Hsu}$ CY, McCulloch CE, Iribarren C, Darbinian J, Go AS: Body mass index and risk for end-stage renal disease. Ann Intern Med 2006;144:21-28.

23 Bucaloiu ID, Perkins RM, DiFilippo W, Yahya T, Norfolk E: Acute kidney injury in the critically ill, morbidly obese patient: diagnostic and therapeutic challenges in a unique patient population. Crit Care Clin 2010;26:607624.

24 Hsu CY, Bansal N: Measured GFR as 'gold standard' - all that glitters is not gold? Clin J Am Soc Nephrol 2011;6:1813-1814.

25 Navaneethan SD, Yehnert H: Bariatric surgery and progression of chronic kidney disease. Surg Obes Relat Dis 2009;5:662-665.

26 Hou CC, Shyu RS, Lee WJ, Ser KH, Lee YC, Chen SC: Improved renal function 12 months after bariatric surgery. Surg Obes Relat Dis 2013;9:202-206.

27 Helal I, Fick-Brosnahan GM, Reed-Gitomer B, Schrier RW: Glomerular hyperfiltration: definitions, mechanisms and clinical implications. Nat Rev Nephrol 2012;8:293-300.

28 Fliser D, Ritz E: Serum cystatin c concentration as a marker of renal dysfunction in the elderly. Am J Kidney Dis 2001;37:79-83.

29 Coll E, Botey A, Alvarez L, Poch E, Quinto L, Saurina A, Vera M, Piera C, Darnell A: Serum cystatin $\mathrm{c}$ as a new marker for noninvasive estimation of glomerular filtration rate and as a marker for early renal impairment. Am J Kidney Dis 2000;36:29-34. 
30 Shlipak MG, Sarnak MJ, Katz R, Fried LF, Seliger SL, Newman AB, Siscovick DS, Stehman-Breen C: Cystatin $c$ and the risk of death and cardiovascular events among elderly persons. N Engl J Med 2005;352:2049-2060.

31 Shlipak MG, Matsushita K, Arnlov J, Inker LA, Katz R, Polkinghorne KR, Rothenbacher D, Sarnak MJ, Astor BC, Coresh J, Levey AS, Gansevoort RT, Consortium CKDP: Cystatin $\mathrm{c}$ versus creatinine in determining risk based on kidney function. N Engl J Med 2013;369: 932-943.

32 Preiss DJ, Godber IM, Lamb EJ, Dalton RN, Gunn IR: The influence of a cooked-meat meal on estimated glomerular filtration rate. Ann Clin Biochem 2007;44:35-42.

-33 Vinge E, Lindergard B, Nilsson-Ehle P, Grubb A: Relationships among serum cystatin c, serum creatinine, lean tissue mass and glomerular filtration rate in healthy adults. Scand J Clin Lab Invest 1999;59:587-592.

- 34 Groesbeck D, Kottgen A, Parekh R, Selvin E, Schwartz GJ, Coresh J, Furth S: Age, gender, and race effects on cystatin c levels in US adolescents. Clin J Am Soc Nephrol 2008;3:17771785 .
35 Macdonald J, Marcora S, Jibani M, Roberts G, Kumwenda M, Glover R, Barron J, Lemmey A: GFR estimation using cystatin $\mathrm{c}$ is not independent of body composition. Am J Kidney Dis 2006;48:712-719.

36 Thurlow JS, Abbott KC, Linberg A, Little D, Fenderson J, Olson SW: SCr and SCysC concentrations before and after traumatic amputation in male soldiers: a case-control study. Am J Kidney Dis 2013, E-pub ahead of print. 37 de Aquino LA, Pereira SE, de Souza Silva J, Sobrinho CJ, Ramalho A: Bariatric surgery: impact on body composition after roux-en-y gastric bypass. Obes Surg 2012;22:195-200.

38 Stevens LA, Schmid CH, Greene T, Li L, Beck GJ, Joffe MM, Froissart M, Kusek JW, Zhang YL, Coresh J, Levey AS: Factors other than glomerular filtration rate affect serum cystatin c levels. Kidney Int 2009;75:652-660.
39 Naour N, Fellahi S, Renucci JF, Poitou C, Rouault C, Basdevant A, Dutour A, Alessi MC, Bastard JP, Clement K, Guerre-Millo M: Potential contribution of adipose tissue to elevated serum cystatin $c$ in human obesity. Obesity (Silver Spring) 2009;17:2121-2126.

40 Levey AS, Kramer H: Obesity, glomerular hyperfiltration, and the surface area correction. Am J Kidney Dis 2010;56:255-258.

41 Friedman A: The importance of considering metabolism when indexing the glomerular filtration rate. Am J Kidney Dis 2010;56:1218.

42 Delanaye P, Radermecker RP, Rorive M, Depas G, Krzesinski JM: Indexing glomerular filtration rate for body surface area in obese patients is misleading: concept and example. Nephrol Dial Transplant 2005;20:2024-2028.

43 Ravussin E, Bogardus C: Relationship of genetics, age, and physical fitness to daily energy expenditure and fuel utilization. Am J Clin Nutr 1989;49:968-975.

44 Friedman AN, Quinney SK, Inman M, Matter SG, Shihabi Z, Moe S: Influence of dietary protein on glomerular filtration before and after bariatric surgery: a cohort study. Am J Kidney Dis, in press. 